\title{
Perpectives
}

\section{Battle against poliovirus in Pakistan}

\author{
Kaneez Fatima ${ }^{1}$, Ishtiaq Qadri ${ }^{2}$ \\ ${ }^{1}$ IQ Institute of Infection and Immunity, Lahore, Pakistan \\ ${ }^{2}$ King Fahd Medical Research Center, King Abdul Aziz University, Saudi Arabia
}

\begin{abstract}
On 22 Feb 2013, the Polio Monitoring Cell of Pakistan announced that the 2012-2013 polio campaign ended, and that 1.6 million children could not be vaccinated due to security concerns in several regions where polio workers had been killed. Those who could not be vaccinated included 50,000 children from the Federally Administrated Tribal Area (FATA), 150,000 form Khyber Pakhtoon Khao, 400,000 from a Quetta, 400,000 from Karachi, and a small number from the Rawalpindi District. These statistics are worrying, as several districts in the large metropolitan cities of Karachi and Quetta were also excluded. The fear of advanced medicine, ideas, or complex devices is a new phenomenon in many conservative and poor countries such as Pakistan, Afghanistan, Sudan, and Somalia. To safeguard the safety of the rest of the world, the failure in the implementation of WHO guidelines for vaccination must be regulated by the UN. There are a number of reasons for the phobias surrounding vaccination, but as technology continues to evolve at such a rapid rate, those with self-determined ideologies cannot cope with such advances. They become vocal to gain popularity and prevent the use of these technologies and medicine by creating and spreading rumors and propaganda of expediency. The struggle to vaccinate children is not easily understood by anyone living in the developed world. The irrational fear of vaccines and the lack of vaccination pose a serious global health risk and must be curbed through a wide variety of pro-vaccination media and religious campaigns.
\end{abstract}

Key words: oral poliovirus vaccines; FATA; WHO; polio P3 strain

J Infect Dev Ctries 2013; 7(11):897-899. doi:10.3855/jidc.3647

(Received 09 April 2013 - Accepted 26 July 2013)

Copyright (C) 2013 Fatima et al. This is an open-access article distributed under the Creative Commons Attribution License, which permits unrestricted use, distribution, and reproduction in any medium, provided the original work is properly cited.

The 19th century witnessed the rapid rise of modern science with the work of great scientists such as Louis Pasteur, Charles Darwin, Michael Faraday, Gregor Mendel, Henri Becquerel, Marie Curie, and inventors such as Nikola Tesla, Thomas Edison and Alexander Graham Bell. Serious efforts were made in the medical field with the pioneering work of Jonas Salk to develop a polio vaccine following the development of vaccines against meningitis, measles, and the hepatitis B virus (HBV). This global effort saved billions of lives who otherwise would have perished from crippling and devastating infections [1]. However, during this time, the world changed rapidly for Muslim regions, which had largely remained isolated from the progress in medical and technological development due to non-participation; thus, fear and resentment started. Those professing leading a simple life and think of it beyond death, rather that make it complex due to medical intervention, had a romantic but realistically a cynical view of our existence. Muslims have distinguished between scientific medicine and prophetic medicine attributed to the Muslim prophet Muhammad over the centuries [2]. These rejectionists of modern medicine were ignorant of the fact that in the hadith, Muhammad had recommended the use of honey and hijama (wet cupping) for healing [3]. The existence of a cause and a cure for every disease is described in many hadith [4] and it is clearly stated in many hadith that there is no disease that the Creator created for which he did not also create a treatment [5]. The rest of the world struggles to understand why certain Muslim groups in Pakistan have rejected the use of vaccines against the polio virus, which has saved the lives of millions of children.

It is notorious that poliovirus has affected nearly all children and over $90 \%$ of adults. The virus resides in the intestinal tract or in the nose or throat mucus of the infected person, and transmission often occurs through fecal-oral transmission [6]. Furthermore, the shed virus is routinely found in sewage water, and transmission can occur through contact with infected respiratory secretions. Droplets from the sneeze or cough of an infected person may spray into the air and the infected mucus or saliva can reach other people's noses or throats. Once the poliovirus enters the body, 
Table 1: Wild polio cases in Pakistan (2009-2013)

\begin{tabular}{|c|c|c|c|c|c|c|c|c|c|c|c|c|c|c|c|}
\hline \multirow{2}{*}{ Province/Region } & \multicolumn{5}{|c|}{ Polio 1 (P1) } & \multicolumn{5}{|c|}{ Polio 3 (P3) } & \multicolumn{5}{|c|}{ Total Cases } \\
\hline & 2009 & 2010 & 2011 & 2012 & 2013 & 2009 & 2010 & 2011 & 2012 & 2013 & 2009 & 2010 & 2011 & 2012 & 2013 \\
\hline Punjab & 16 & 6 & 9 & 2 & 1 & 1 & 1 & 0 & - & - & 17 & 7 & 9 & 2 & 1 \\
\hline Sindh & 7 & 26 & 33 & 4 & 1 & 5 & 1 & 0 & - & - & 12 & 27 & 33 & 4 & 1 \\
\hline FATA & 8 & 63 & 57 & 17 & - & 12 & 11 & 2 & 3 & - & 20 & 74 & 59 & 20 & - \\
\hline KP & 24 & 19 & 23 & 25 & 3 & 5 & 5 & 0 & - & - & 29 & 24 & 23 & 25 & 3 \\
\hline GILGIT BALTISTAN & 0 & 0 & 1 & 1 & - & 0 & 0 & 0 & - & - & 0 & 0 & 1 & 1 & - \\
\hline Islamabad & 0 & 0 & 0 & - & - & 0 & 0 & 0 & - & - & 0 & 0 & 0 & - & - \\
\hline
\end{tabular}

it travels from the oral cavity to the pharynx and intestines, where it begins to multiply and travel to other parts of the body. The symptoms of polio, on average, begin to show between 7 and 14 days after infection; however, the polio incubation period can range between 4 and 35 days [7].

Despite the dedication to the elimination of poliovirus, it remains a daunting task in Pakistan [8]. In 1994, National Immunization Days (NIDs) were initiated, during which all children five years of age of younger were given oral polio virus vaccines (OPV3); since then, over 20 million children have been vaccinated each year. As a result, there was a significant decline in the number of polio cases throughout the nation since 2007 [9]. In 2010, however, there were 144 children across Pakistan who were paralyzed due to the virus, over half of whom were from FATA, and seventeen per cent were from Khyber Pakhtunkhwa (Table 1). Many people in Pakistan protested against the polio vaccine because a large section of the Pakistani population is unaware of the existence of a polio vaccine, according to UNICEF. This lack of understanding has posed a serious threat to the lives of people in the health care sector. The cascade of events that have led to attacks began, and in several such incidents, health care workers, law enforcers, and UN agencies were vulnerable to attacks. On July 2012 in Islamabad, an anti-polio worker was attacked; a day later, a UN doctor was shot in Karachi. In Dec 2012, nine polio health workers, including five female health workers and one 17-year-old school girl volunteer were killed. In March 2013, while protecting a polio team, a Pakistani policeman was shot dead in the same vicinity, bringing the number of deaths in such attacks in the country to 20 over the last year.

P1 and P3 strains remain endemic in only three countries - Pakistan, Afghanistan, and Nigeria. In
2012, a new strain of polio (P3) was found in the tribal regions of Pakistan; this strain had been eradicated across the world in the 1980s. However, in 2013, the WHO announced that P3 had been eradicated in Pakistan with the constant supervision of WHO teams in spite of security issues and the political crisis. Similarly, the statistics of P1 released in October 2012 also showed an improvement in the polio situation in Pakistan, with 47 children paralyzed by the disease in 27 districts compared with 154 cases in 48 districts in 2011.

After a decades-long struggle by multilateral organizations, governments, and non-governmental organizations worldwide, the spread of wild type poliovirus has been eliminated from many countries except for Pakistan, Afghanistan and Nigeria, where vaccine-derived strains that cause similar diseases still exist. The polio vaccine can help to protect children from disability; the polio campaign should therefore be implemented in Pakistan without resistance to the vaccine.

Finally, it is the responsibility of law enforcing agencies in Pakistan to stop the killing of health care workers [10]; however, a different approach should be considered. The campaign should emphasize the fact that the polio vaccine has been used for a long time all over the world, including in more than fifty Muslim countries, and has proven to be highly effective in eradicating the polio and many other diseases [11-12]. The common belief is that polio vaccination programs are run by the agencies of countries and that aid workers may have ties with spy agencies. This misconception must be dispelled through a clear message that vaccination programs are operated only by medical authorities to control the spread of serious viral disease such as polio. With effective social and religious campaigns, it is likely that a small band of anti-vaccine groups will accept the fact that vaccinations are for the benefit of children and will 
help to ensure a healthy future generation rather a crippled nation.

\section{Acknowledgements}

The authors wish to thank the Polio Monitoring Cells of Pakistan, Dr. Zainab Younas of Allama Iqbal Medical College, Lahore; Miss Nadia Rashid of IQ Institute of Infection and Immunity; and Dr. Badr Younas of Rawalpindi Medical College, Rawalpindi for their valuable suggestions and helpful discussion.

\section{References}

1. Justin S (2011) Writing the History of the Natural Sciences in the Pre-modern Muslim World: Historiography, Religion, and the Importance of the Early Modern Period. History Compass 9: 923-951.

2. Sayeed MD (1980) Traditional medicine in health care. J Ethnopharmacol 2: 19-22.

3. Elgood C (1962) The Medicine Of the Prophet. PubMed Central 146-153.

4. Nurdeen D (2003) Ahadith of the Prophet on Healing in Three Things (al-Shifa' fi Thalatha). Journal of the International Society for the History of Islamic Medicine 4: 14-20.

5. Rosenthal F, Marmorstein J (1975) The classical heritage in Islam. Berkeley: University of California Press. p. 182.
6. Angez M, Shaukat S, Alam MM, Sharif S, Khurshid A, Zaidi SS (2012) Genetic relationships and epidemiological links between wild type 1 poliovirus isolates in Pakistan and Afghanistan. Virol J 9: 51-67.

7. De Jesus NH (2007) Epidemics to eradication: the modern history of poliomyelitis. Vir J 4: 70-88.

8. Schuchat A (2013) The state of immunization 2013: we are the world. S D Med Spec no: 27-32.

9. Habib MA, Soofi S, Ali N, Sutter RW, Palansch M, Qureshi H, Akhtar T, Molodecky NA, Okayasu H, Bhutta ZA (2013) A study evaluating poliovirus antibodies and risk factors associated with polio seropositivity in low socioeconomic areas of Pakistan. Vaccine 31: 1987-1993.

10. Bhutta ZA (2013) What must be done about the killings of Pakistani healthcare workers? BMJ 346:f280.

11. Borchardt JK (2002) Arabic Pharmacy during the Age of the Caliphs. Drug News Perspect 15: 383-388.

12. Goodyear AC (2008) From Technophilia to Technophobia: The Impact of the Vietnam War on the Reception of "Art and Technology". Leonardo 41: 169-173.

\section{Corresponding author}

Ishtiaq Qadri

King Fahd Medical Research Center

King Abdul Aziz University

PO Box 80216, Jeddah 21589

Saudi Arabia

Email: ishtiaq80262@yahoo.com

Conflict of interests: No conflict of interests is declared. 